\title{
A Novel Approach for Distribution Fault Analysis
}

Mo-yuen Chow

IEEE Member

Dept. of Electrical and Computer Engineering

North Carolina State University

Raleigh, NC 27695-7911

\section{Abstract}

This paper proposes to use four different measures : actual values, normalized values, relative values, and likelihood values for power systems' distribution faults analysis. This paper also discusses the general and local properties of distribution faults. The likelihood measure, based on the local region properties, provides important information for distribution fault cause identification when the fault cause is not known. Tree faults on the Duke Power System are used in this paper for illustration purposes. The proposed measures, analysis and discussion in this paper can be easily generalized for different types of distribution faults in other utility companies.

\section{Introduction}

Distribution faults have been significantly affecting power systems' reliability, security and quality, among other important factors. At Duke Power Company, with distribution systems in North Carolina and South Carolina as shown in Fig. 1, there are 1,787 circuits, 1,694,557 customers, 265,472 fuse locations, 4,295 recloser locations, 501,073 overhead transformers, 91,916 underground transformers, and 55,436 primary line miles (including overhead and underground cables). There are, on the average, 40,000 permanent distribution faults, 30,000 major temporary faults that trip the main circuit breakers and 75,000 minor temporary faults that trip line breakers (reclosers) each year. Likewise, many other utility companies also experience a large number of distribution faults in their systems. In the area of power quality and reliability of distribution circuits, there is significant emphasis on techniques and technologies that can be used in reacting to utility system faults. Examples are circuit coordination techniques, distribution automation technology and UPS system installations. The paradigm in which these techniques operate is one in which the fault is considered an inevitable event that must be dealt with by reacting to the fault or to the result of the fault, which is usually an outage or a voltage sag.

93 WM 089-3 PWRD A paper recommended and approved by the IEEE Transmission and Distribution Committee of the IEEE Power Engineering Society for presentation at the IEEE/PES 1993 Winter Meeting, Columbus, OH, January 31 - February 5, 1993. Manuscript submitted August 31, 1992; made available for printing November 23, 1992.
Leroy S. Taylor

IEEE Member

Power Delivery Engineering Service

Duke Power Company

Charlotte, NC 28201-1010

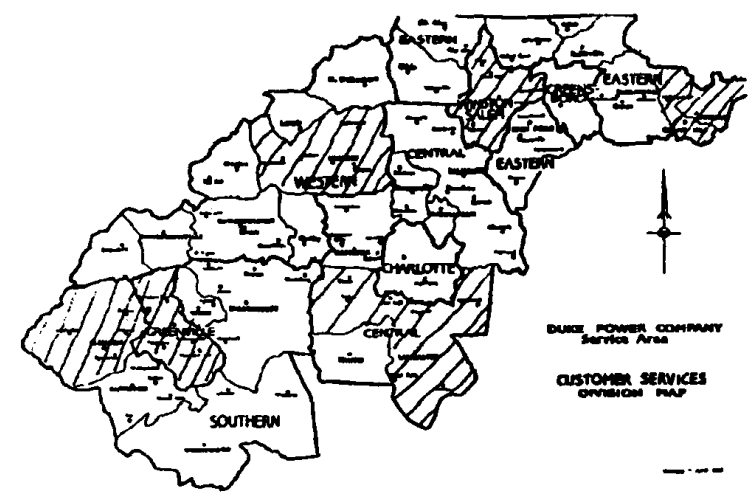

Fig 1 : Duke Power Company Customer's Services Division Map.

While there is little argument over the inevitability of faults occurring in the distribution system, there are distinct disadvantages in completely relying on those techniques that react to these faults. One example that has been given recently is the trade-off between fuse savings and momentary outages [8]. Removal of feeder selective relaying can save momentary interruptions for large numbers of customers, but can also cause additional sustained interruptions. In this example, a decrease in momentary interruptions is traded for an increase in sustained interruptions. However, there is a paradigm of distribution power quality and reliability that does not require a trade-off in this situation. This paradigm is termed fault prevention. In other words, if the fault that blew the fuse is prevented to begin with, then the fuse will not blow, and neither a sustained nor a momentary interruption will occur.

Fault analysis techniques aim at the prevention of faults through better understanding of the causes. Other techniques that fall in the fault prevention paradigm include fault location, preventive maintenance techniques, and improved line and equipment designs. All these techniques and technologies are important in the reduction of fault sources. In order to improve line and equipment designs to prevent faults in the distribution system, it is necessary to find and inspect the known fault locations at the site of the fault. Based on these investigations, existing designs can be evaluated and changed if necessary. For example, it has been observed that some underground riser poles of older design 
have bare lead wires that come very close to fuse mounting brackets. In addition, these mounting brackets are sometimes grounded unintentionally. In the past, animals have gotten between these bare lead wires and the brackets, causing distribution faults. Indications of this problem first appeared as a pattem of animal outages around underground riser poles. As a result of this discovery, the new underground riser design uses insulated lead wires and increased clearance to the brackets, thus preventing the animal faults. In addition, the older riser poles have been retrofitted to correct the problem.

As in the above example, detailed site investigations and analysis of existing outage records can provide a great deal of information about fault causes. Each record represents an on-site visit by a line technician. While the main job of the technician is to restore service, it is also a part of his job to inspect the site for the outage causes. However, the line technician is not always able to evaluate the design flaw that led to the outage. This job falls to the reliability engineer. By seeing patterns in the existing outage records, the reliability engineer can initiate more detailed investigations that will result in designs that reduce the likelihood of faults.

While some studies have been done on power system faults $[1-4,8]$, more knowledge of distribution faults are needed. Better understanding of causes and consequences of distribution faults will be helpful for distribution system maintenance and future system design in terms of reliability (avoiding repeated outages caused by failure to identify fault causes), protection devices installation (which can save a lot of money by placing the correct protection devices and avoiding installation of unnecessary protection devices), and environmental issues (such as whether to trim trees or not), among others. With as many as 40,000 outage reports per year on the Duke Power System, there is a lot of information to evaluate. This paper will address the analysis of distribution faults from a quantitative approach using historical data, from a qualitative approach based on experience, and from a heuristic point of view. The analysis will be focused on four measures : (1) actual number of faults, (2) normalized number of faults, (3) relative number of faults, and (4) likelihood of faults. The likelihood measure is a very different measure from the conventional point of view. The measure is particularly useful if a distribution fault occurs and its cause is not exactly known. The likelihood measure can give a reasonable estimate of the distribution fault cause. (The likelihood concept has been used to train artificial neural networks to identify animalcaused distribution faults, yielding highly satisfactory results [7].) The four measures and their analysis will be discussed in later sections. The analytical approach and results discussed in this paper can be easily generalized to different distribution faults in different utility companies.

\section{Distribution Fault Records on the Duke Power System}

Distribution faults data are recorded on the Duke Power System each time a fault current is detected in the distribution system as a result of the operation of a breaker relay, fuse, or another protective device. The recorded data contains information such as geographical location, circuit ID number, weather condition, and time of the fault occurrence. Twenty-two information items are recorded for each outage at Duke Power Company, which are obtained as follows. Some of the information is based on a coding system, designed by Duke Power engineers and summarized in charts, that describes the circumstances under which the outages occurred (e.g., weather condition, season of the year, time of the day). Other information items are based on data collected by equipment that monitors the operation of the distribution system (e.g., number of phases affected, protective devices used). Distribution fault causes are divided into 11 categories (Table 1). Once a permanent fault is detected, crewmen are dispatched to restore/repair the system as well as to find the fault causes, if possible. In many cases, some evidence is left when a permanent fault occurs. For instance, if a transformer fuse is blown and a dead squirrel's body is found near the transformer, it is strong evidence to suggest that the fault was caused by an animal. In this case, crewmen will then input code 4-animal fault into the database. Another example is a lightning fault which results in a burn mark on the pole or insulation; then the crewman will input code 0-Duke Power Equipment failure (caused by lightning) into the database. In some cases, however, evidence may not be found. The service crewmen may lack the knowledge to deduce the fault cause from the available clues, in which case the crewman will enter code 11 - unknown reason as the cause of the fault. With a better understanding of the fault causes in the distribution area, the size of the unknown reason category can be significantly reduced.

Table 1 : Duke Power Distribution Systems fault cause code

\begin{tabular}{|l|l||l|l|}
\hline code & cause & code & cause \\
\hline \hline 00 & $\begin{array}{l}\text { Duke equipment } \\
\text { failure }\end{array}$ & 07 & $\begin{array}{l}\text { planned (maintenance or } \\
\text { operation) }\end{array}$ \\
\hline 01 & $\begin{array}{l}\text { customer } \\
\text { equipment failure }\end{array}$ & 08 & Duke accident \\
\hline 02 & overload & 09 & public accident \\
\hline 03 & trees & 10 & vandalism \\
\hline 04 & animal & 11 & unknown cause \\
\hline 05 & $\begin{array}{l}\text { planned (new } \\
\text { installation) }\end{array}$ & & \\
\hline
\end{tabular}

Seven regions of the Duke Power System were chosen for detailed fault analysis : Chapel Hill (CHPL), Clemson (CLEM), Durham (DURH), Greenville (GREE), Hickory (HICK), Lancaster (LANC) and Winston-Salem (WINS), shown as the cross-hatched areas in Fig. 1 and with the characteristics listed in Table 2 . These chosen regions are reasonable representations of Duke Power's eastern region, central region, and mountain area; these regions also 
cover metropolitan areas, cities, small towns, rural areas and wooded areas; new systems and old systems; different types of customers, etc. The distribution fault data between 1989 and 1990 of the seven regions are used for investigation in this paper. The time period covered is representative of Duke Power's typical distribution faults for different weather, seasons, days and times.

Table 2 : Characteristic of the seven distribution regions under investigation.

\begin{tabular}{|c|c|c|c|c|c|c|c|}
\hline & $\begin{array}{l}\text { Fof } \\
\text { circ- } \\
\text { vits }\end{array}$ & $\begin{array}{l}\text { of } \\
\text { custom- } \\
\text { ers }\end{array}$ & $\begin{array}{l}\text { Fof } \\
\text { fuse } \\
\text { loca- } \\
\text { tions }\end{array}$ & $\begin{array}{l}\text { \%of } \\
\text { recloser } \\
\text { loca- } \\
\text { tions }\end{array}$ & $\begin{array}{l}\text { of } \\
\text { over- } \\
\text { head } \\
\text { trans- } \\
\text { formers }\end{array}$ & $\begin{array}{l}\text { of } \\
\text { under- } \\
\text { ground } \\
\text { trans- } \\
\text { formers }\end{array}$ & $\begin{array}{l}\text { pri- } \\
\text { mary } \\
\text { line } \\
\text { miles }\end{array}$ \\
\hline $\begin{array}{l}\text { Chapel } \\
\text { Hill }\end{array}$ & 28 & 32314 & 3862 & 68 & 6448 & 2910 & 875 \\
\hline Clemson & 26 & 27058 & 3110 & 82 & 8890 & 2005 & 1023 \\
\hline Durham & 88 & 89816 & 9788 & 88 & 17892 & 6806 & 1815 \\
\hline Greenvile & 135 & 130811 & 78579 & 188 & 38955 & 6200 & 3409 \\
\hline Hickory & 98 & 80694 & 14302 & 172 & 26383 & 4157 & 2956 \\
\hline Lancaster & 66 & 54565 & 12193 & 269 & 22582 & 2458 & 2631 \\
\hline Winston & 153 & $149810^{\circ}$ & 21527 & 279 & 37921 & 8121 & 4124 \\
\hline
\end{tabular}

The actual distribution fault data of each chosen region is depicted in Fig. 2. As shown in this figure, Duke Power equipment failure causes (code 0 ) constitutes the majority of the fault causes. The category of Duke equipment failure is very broad and diversified, ranging from transformer failure to underground cable failure. Other than the Duke Power equipment failure, tree faults and animal faults are probably the most frequent faults in the distribution systems, making up more that $30 \%$ of the total faults that occur in the Duke Power System. This paper will focus on the analysis and discussion of tree faults using the available fault data for illustration purposes. The analytical approach and discussion can be easily generalized to other distribution faults in different areas.

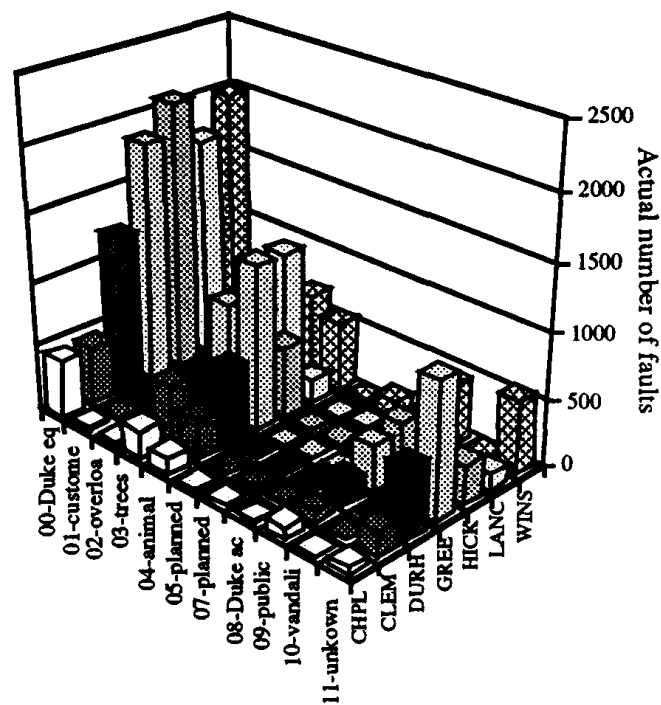

Fig. 2 : Data distribution of the causes of faults in Duke Power Distribution Systems.

\section{Distribution Faults Analysis}

Based on the data available from the chosen seven regions, tree faults are investigated with respect to six factors : weather condition, season, day, time, number of phases affected, and protection device activated. Among the factors under consideration, the weather condition, season, day and time are grouped as influential factors of tree faults, while the number of phases affected and protection device are grouped as consequence factors, i.e., results of tree faults (Table 3).

Table 3. Influential and consequence factors of tree and animal faults under study.

\begin{tabular}{|l|l|}
\hline Influential factors & Consequence factors \\
\hline \hline weather condition & \# of phase affected \\
\hline season & protection device activated \\
\hline day & \\
\hline time & \\
\hline
\end{tabular}

Four different measures are proposed in this paper for the analysis of distribution faults : (1) actual number of faults, (2) normalized number of faults, (3) relative number of faults, and (4) likelihood of faults. The first measure, actual number of faults, for different conditions (Fig. 2) give many meaningful indications. For example, the actual value can help make decisions such as the installation of animal protection devices in a region where enough animal faults are detected. However, in many cases, the relative importance and/or fault prevention priority is of interest, in which case looking only at the actual values can be misleading. For instance, the fact that the number of tree faults in region $A$ is much higher than in region $B$ does not imply that the tree faults in region $A$ are more severe than in region $B$, because each region and each circuit has its own characteristics, as shown in Table 2. Some of the circuits are larger and serve many customers, while others are small and serve fewer customers; some of the circuits are in urban areas, while others are in rural areas; some of them are newly installed and well protected, while others may be old and not well protected. In order to reduce as many subjective influential factors as possible, sometimes it is more meaningful to investigate the second measure, i.e., normalized measure, of each fault in the system :

$$
N_{F C}=\frac{\# \text { of specific } F C \text { in region } R}{\text { \# of total } F C \text { in region } R} \text { (pu), }
$$

where the specific fault cause $(F C) \in$ \{tree fault\} in this paper. The normalization concept has been used extensively in power systems studies, such as in machine analysis [5].

The third measure is the relative measure of distribution faults of event $x$ that belong to factor $y$ :

$R_{F C, x}=\frac{\# \text { of } F C \text { at event } x \in y \text { in region } R}{\# \text { of total } F C \in y \text { in region } R}$ (pu).

In this paper, $y \in$ (weather condition, season, ..., protection device $\}$ and events for $y=$ weather condition is $x \in\{$ fair, cold, ..., ice \}, etc. This measure gives the relative frequency [6] of event $x$ that occurs in the factor $y$ condition and 
provides more detailed information of fault analysis for each factors being considered in this paper.

The fourth measure used in this paper is the likelihood of the faults given different conditions :

$L F C, x=\frac{\# \text { of } F C \text { at event } x \text { in region } R}{\# \text { of total } F C \text { at event } x \text { in region } R}$ (pu).

The likelihood measure gives the probability of a fault happening, given that a specific event also occurs. For example, if a fault happens in the morning in region $A$, what is the likelihood that the fault was caused by trees? This concept is very useful when a distribution (permanent and/or temporary) fault occurs and the exact cause is not found. Based on some clues left by the fault, such as the six factors under investigation, and based on the likelihood measure of each fault for all fault conditions, the cause of the fault can be well estimated [7]. The use of the likelihood method will be discussed more in later sections.

\section{Tree Faults Data Analysis}

The actual tree fault data with respect to different regions are displayed in Fig. 3a. Each region has a different number of tree faults that is not highly correlated with the size of the service area. This is reasonable because each circuit has its own characteristics, as discussed previously. The tree faults data are normalized according to Eq. (1) and displayed in Fig. 3b. The normalized tree fault distribution can be very different from the actual number of tree faults in different regions, as indicated through the contrast between Fig. 3a and Fig. 3b. For the purposes of detailed fault analysis, the data are also categorized based on the relative measure in Eq. (2) according to different weather conditions, season, day, time, number of phase affected, and protection device activated during the fault (Figs. 4a,b,c,d,e,f).

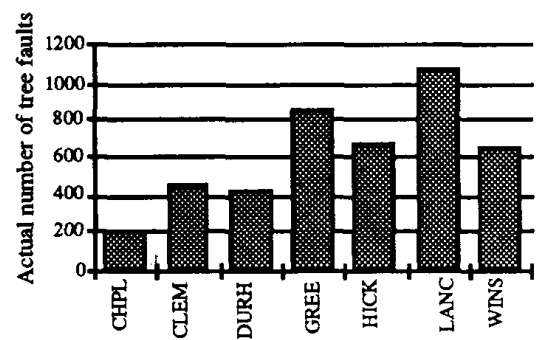

Fig. 3a : Number of tree faults at different regions in year $89-90$

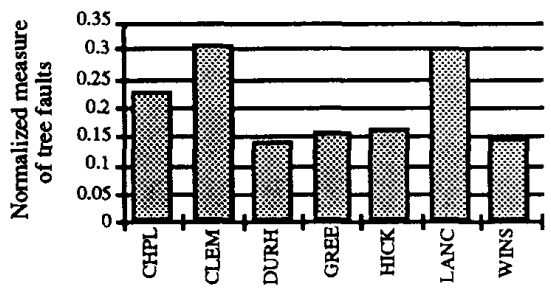

Fig. 3b : Normalized number of tree faults at different regions in year 89-90.

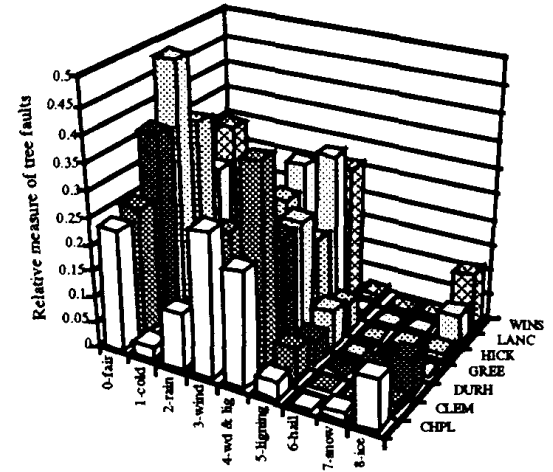

Fig. 4a: Relative tree-fault data with respect to weather in different regiolss.

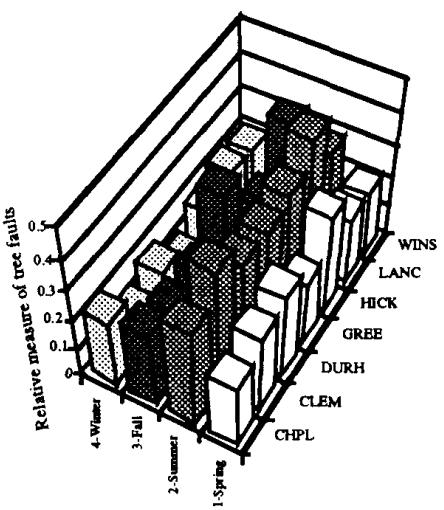

Fig. $4 \mathrm{~b}$ : Relative tree-fault data with respect to season in different regions.

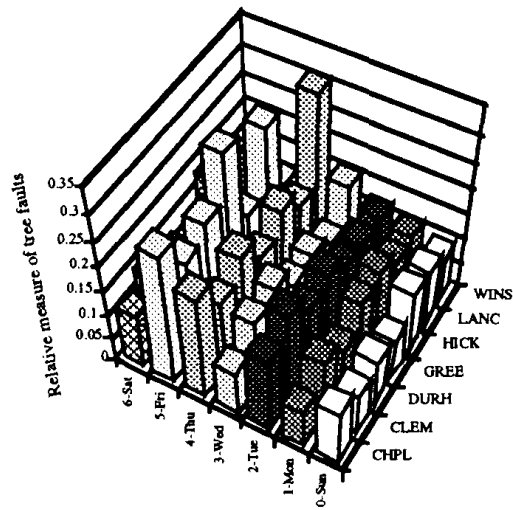

Fig. $4 c$ : Relative tree-fault data with respect to day in different regions. 


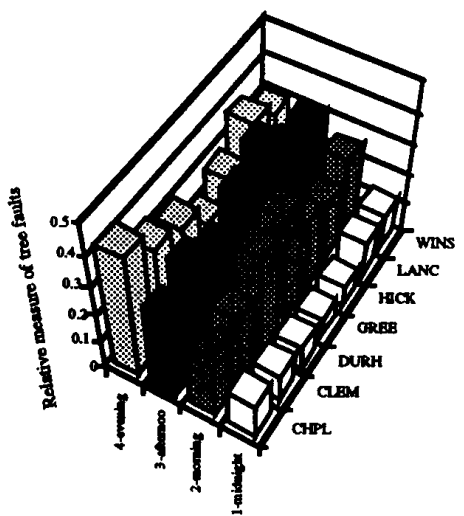

Fig. 4d : Relative tree-fault data with respect to time in different regions.

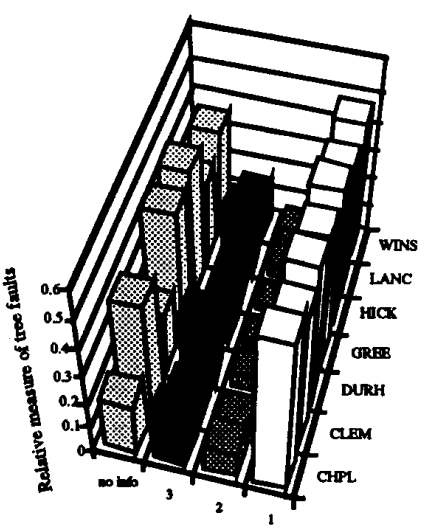

Fig. 4e : Relative tree-fault data with respect to number of phases affected in different regions.

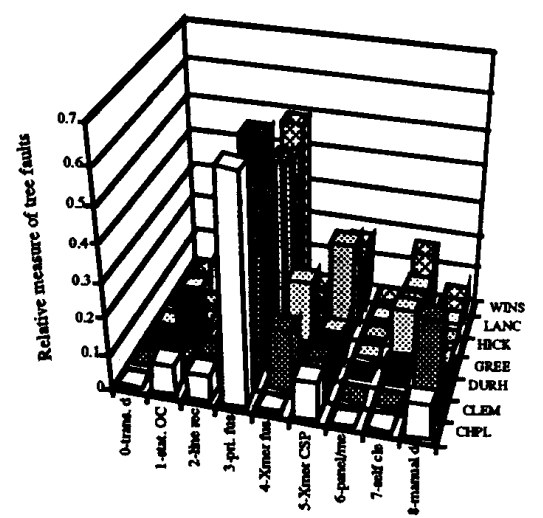

Fig. 4f : Relative tree-fault data with respect to protection devices activated in different regions.

Fig. 4a indicates that tree faults happen often in fair weather, windy weather, windy and lighting weather, and rainy weather. Fig. $\mathbf{4 b}$ indicates Summer has the most number of tree faults while Winter has the least. Fig. 4c basically indicates that the tree faults are not greatly influenced by the day of week. Fig. $4 d$ indicates that on the average more tree faults occur in the afternoon and evening than at midnight. Fig. 4e clearly indicates that when a tree fault occurs, it usually trips only one phase, maybe three phases, but rarely 2 phases. Fig. $4 \mathrm{f}$ indicates that the protection device that tree faults activate is mainly the primary fuse, and to a lesser degree station OCB, line reclosers, transformer CSP and manual devices.

However, looking only at the number of fault events (even with normalized measure and relative measure) under different conditions sometimes is misleading if the results are not interpreted correctly. For example, it contradicts our intuition that so many tree faults occur in fair weather, while only a small number of tree faults in snowy conditions (Fig. 4a). Actually, snow heavily influences tree faults occurrence, but there is not much snow in the Duke Power areas. Snow and ice add weights to the trees, thus causing faults; wind is also a major factor that causes tree faults. In order to compensate for this effect, the tree faults are further normalized for specific events with respect to the total number of faults occurring for the specific event and is termed the likelihood of fault occurrence given the specific event $x$, denoted by $L_{F C} x$ as mentioned in Eq. (4) of section III. The likelihood measures of the tree faults in Figs. 4a-4f are shown in Figs. 5a-5f respectively.

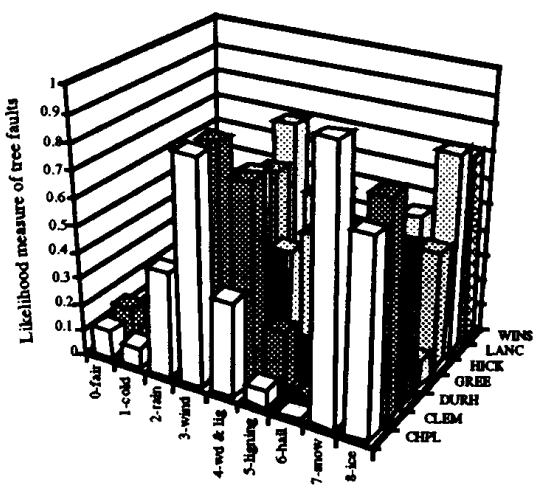

Fig. 5a : Likelihood of tree faults with respect to weather in

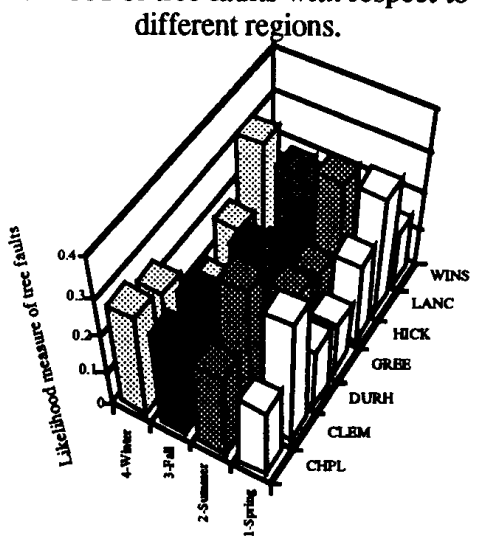

Fig. 5b : Likelihood of tree faults with respect to season in different regions. 


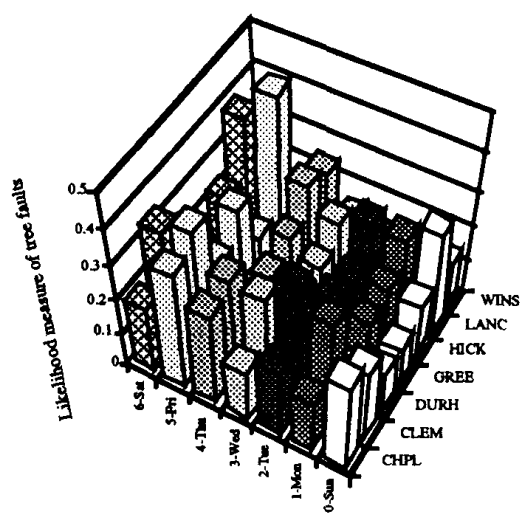

Fig. 5c : Likelihood of tree faults with respect to day in different regions.

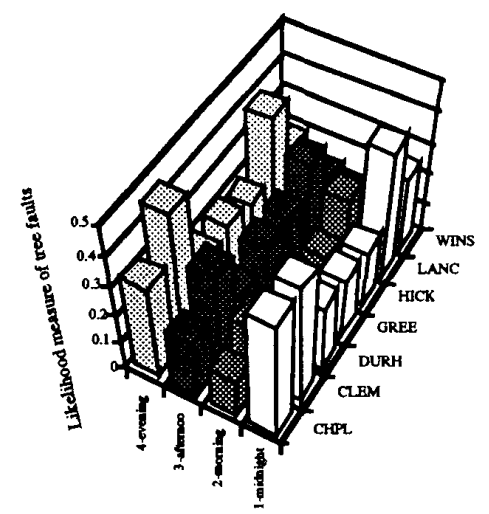

Fig. 5d : Likelihood of tree faults with respect to time in different regions.

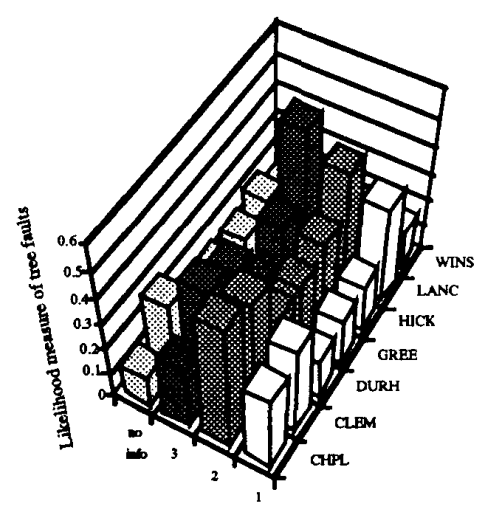

Fig. 5e : Likelihood of tree faults with respect to number of phases affected in different regions.

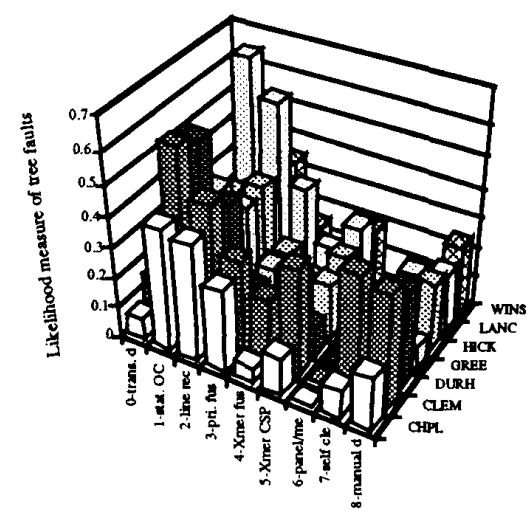

Fig. 5f : Likelihood of tree faults with respect to protection devices activated in different regions.

After obtaining the likelihood measure of tree faults (Figs. 5), some of the results are more meaningful compared to previous measures. Fig. 5a indicates that tree faults are likely to occur in bad weather, especially in snowy, icy and windy conditions, but less likely to occur in fair and cold weather. In Duke Power regions, most of the time the weather is fair, i.e., it has many more faults in fair weather conditions compared to other weather conditions. Even though many tree faults occur in fair weather, as indicated in Fig. 4a, with consideration of other possible faults and the amount of fair weather condition, tree faults are less likely to occur than other faults in fair weather in Duke Power System.

From the investigation of the likelihood of tree faults versus the time of the day, tree faults are found more likely to occur in the evening and during midnight, although this does not mean that tree faults happen more at midnight than in the morning. Using similar arguments with the influence of weather condition in tree faults, when other faults are considered, the tree faults are normalized with respect to those other faults. For example, traffic faults are more likely to occur in the day time because there is more traffic. With the decrease in possibility of traffic faults at night time, relatively speaking, the possibility of tree faults increase at night compared with all other faults.

By looking at the number of phases and protection devices that result from tree faults, we can see that tree faults affect mainly single phase and primary fuses (Figs. 4). But the likelihood measure can provide us with another point of view and another estimate of the cause of the faults. For example, consider two distribution faults that are very similar as far as the six factors are concerned, but one fault activates the line recloser and the other one activates the panel/meter protection device. Then based on Fig. 5f, the first event is more likely to be caused by a tree than the second one. This technique is very useful in finding out the causes of distribution system faults, and it has been used to design a distribution fault cause identifier that has achieved highly satisfactory results for animal-fault identification [7]. 


\section{Local Properties of Distribution Faults}

As discussed in the previous section, some general results that can be drawn from tree fault causes and consequences based on the historical data that is available. However, there are also some factors that do not lead to any general conclusion, but rather depend on individual region/circuit characteristics. One unfortunate tendency that is seen in some literature concerning power quality and reliability is the temptation to make general statements about the causes of faults on the distribution system. Some distribution faults knowledge is quite localized. Expert knowledge in one region may not be generally applicable to another. For example, by examining the likelihood measure of the tree outages of Chapel Hill and Clemson (two similarly sized regions but in different geographical locations, as shown in Fig. 1 and Table 2), it indicates that there is a seasonal difference. The expert at Chapel Hill may gain an intuitive grasp that tree faults, as a subset of all faults, are not necessarily more likely in Summer than in Winter. In fact, based on the total faults that occur in a given season, a tree fault is more likely in the Winter in the Chapel Hill area. On the other hand, the expert at Clemson learns a different lesson. Previous figures indicate a greater likelihood of tree faults occurring in the Summer than in Winter, at least in Clemson. If these experts share their experiences, then each may think that the other is incorrect. In reality, they are both correct about their respective regions. The difference may lie in certain details that are not immediately apparent. These details could include the total number of trees present, the quantity of trees near the lines, the right of way widths, the effectiveness of the tree maintenance programs, or the difference in line designs. It is also possible that no experts at Clemson or Chapel Hill have noticed this subtle difference in the tree fault pattern. In this case, the analysis may be pointing to a footprint for an effective tree program, or perhaps even a footprint of an overly expensive tree program.

Another example of inadequate analysis is in the assumption that tree faults occur in fair weather. If a circuit is being subjected to momentary interruptions, even if the fault occurs in fair weather, there is an immediate assumption that tree work is needed. However, as can be seen from the likelihood measure of tree faults in fair weather, this assumption is probably wrong. None of the districts analyzed in this paper has a tree fault likelihood of more than $15 \%(0.15 \mathrm{PU})$ in fair weather. At the same time, there are much higher likelihood numbers for tree outages in stormy weather. The immediate message in this instance is that if there are faults in fair weather, do not assume it is tree problems as a first hypothesis. Furthermore, tree work can be very expensive. Look for something else. What time of day do the faults occur? On the Duke Power System, if the faults are occurring in the moming during fair weather, then animal protectors are probably needed rather than tree work (based on the authors' analysis on animal faults, among others).

\section{Conclusion}

In this paper, four different measures : actual values, normalized values, relative values, and likelihood values have been proposed for distribution faults analysis. This paper has also discussed the general and local properties of distribution faults. The likelihood measure, based on the local region properties, provides important information for distribution fault cause identification when the fault cause is not known. Tree faults on the Duke Power System are used in this paper for illustration purposes. The proposed measures, analysis and discussion in this paper can be easily generalized for different types of distribution faults in different utility companies.

\section{Acknowledgment}

The authors of this paper would like to acknowledge the support of Electric Power Research Center project grant 5-31294, North Carolina State University and Duke Power Company project grant 5-30550. The authors would also like to thank Dr. Duncan Fong for his discussions and also the reviewers of this paper for their valuable time, comments and suggestions.

\section{References}

[1] J.J. Burke, D.A. Douglass, D.J. Lawrence, Distribution Fault Current Analysis, EPRI EL-3085, Research Project 1209-1, Final Report, May 1983.

[2] J.G. Anderson, P.P. Barker, I.S. Grant, D.J. Lawrence, Characteristics of Lightning Surges on Distribution Lines, EPRI EL-6782, Research Project 2542-1, Interim Report, May 1990.

[3] IEEE Tutorial Text, Detection of Downed Conductors on Utility Distribution Systems, Course Text 90EH0310-3-PWR.

[4] Leroy S. Taylor, "Finding the Exact Cause of Fault Currents," Duke Power Company Technical Report, February, 1988.

[5] G.R. Slemon, A. Straughen, Electric Machines, Addison-Wesley Publishing Company, 1980.

[6] E. R. Dougherty, Probability and Statistics for the Engineering. Computing, and Physical Sciences, Prentice Hall, 1990.

[7] Mo-yuen Chow, Sui Oi Yee, Leroy S. Taylor, "Recognizing Animal-Caused Faults in Power Distribution Systems Using Artificial Neural Networks," presented in PES SM, 1992, Seattle, WA; to be published in IEEE Transactions on Power Delivery.

[8] Cheryl M. Warren, "The Effect of Reducing Momentary Outages on Distribution Reliability Indices," T\&D Exposition, Dallas, TX, September, 1991. 


\section{Biography}

Mo-yuen Chow

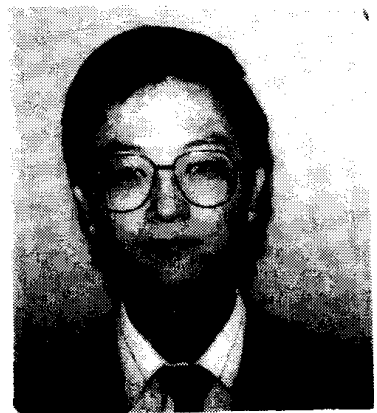

Mo-yuen Chow earned the B.S. degree at University of Wisconsin-Madison (June 1982), M. Eng. degree at Cornell University (August 1983), and Ph.D. degree at Comell University (August 1987), all the degrees are in Electrical Engineering. After graduation, he joined the faculty of North Carolina State University. Currently, Dr. Chow is an Assistant Professor in the Electrical and Computer Engineering Department at North Carolina State University. $\mathrm{He}$ is also the Principal Investigator of various research projects. His research interests include : Power System Analysis, System Monitoring and Fault Detection, Artificial Neural Networks, Fuzzy Logic, Rotating Machines Analysis, System and Control Theory.

\section{Leroy S. Taylor}

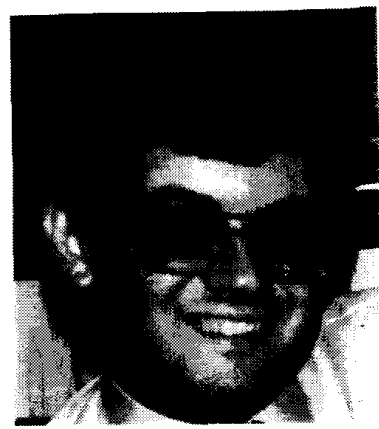

Leroy S. Taylor is a Senior Distribution Engineer for Duke Power Company, and is a registered professional engineer in North Carolina. He was born in 1949 in Greenville, N.C. and received a B.A. degree (Physics) from the University of North Carolina in 1971. Joining Duke Power in 1977, he acquired extensive experience in distribution system engineering, operation, and construction. Since 1987 he has conducted intensive investigations on the cause of power quality disturbances which originate in the distribution system. He has also redesigned several Duke Power mainframe reporting systems used to evaluate and improve distribution system reliability and power quality. 